\title{
Right wrist swelling in a 77-year-old woman
}

\author{
Matthew Morris • Peter M. Murray • Mark Kransdorf
}

Received: 29 April 2011 /Revised: 18 May 2011 / Accepted: 4 July 2011 /Published online: 12 August 2011

(C) ISS 2011

\section{Question}

A 77-year-old woman developed right wrist swelling after catching her wrist in a falling rack of clothes. The patient

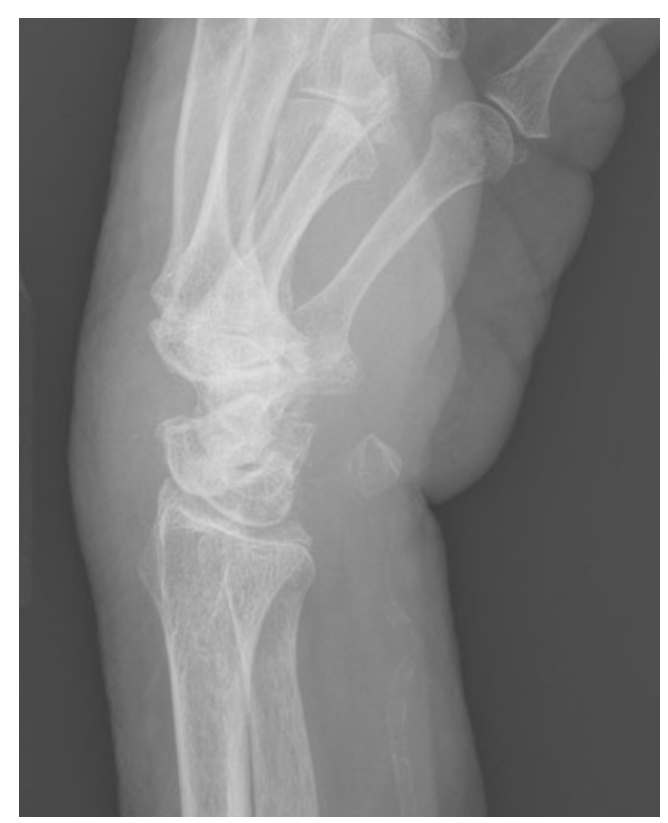

Fig. 1 Oblique radiograph of the right wrist

The diagnosis can be found at doi:10.1007/s00256-011-1229-9.

M. Morris · P. M. Murray $(\bowtie) \cdot$ M. Kransdorf

Department of Orthopedics, Mayo Clinic,

4500 San Pablo Road South,

Jacksonville, FL 32224, USA

e-mail: murray.peter@mayo.edu did not initially experience wrist pain, but developed moderate to severe pain in the ensuing week, causing her to present to the emergency department (Figs. 1,2). What is the diagnosis?

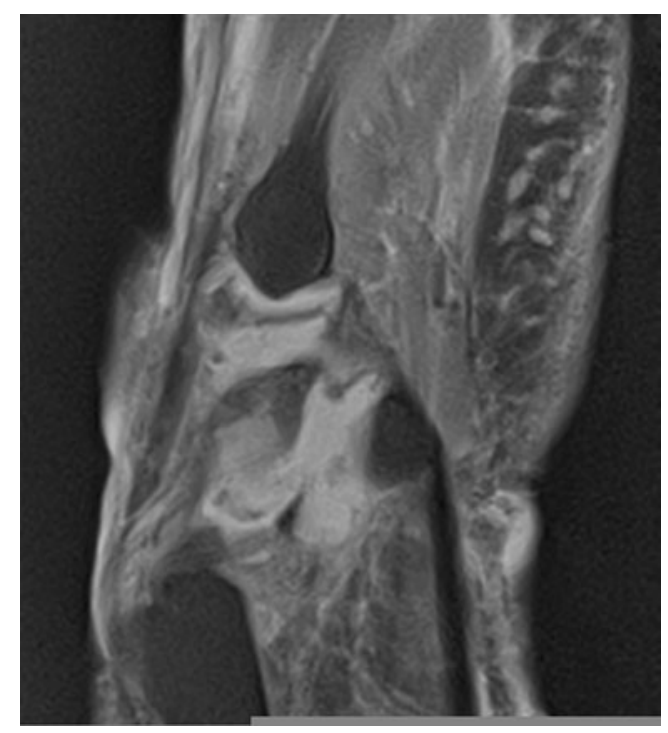

Fig. 2 Proton density fat-saturated T2-weighted MRI of the right wrist in the sagittal plane 